\title{
Correction to "The GPR40 Full Agonist SCO-267 Improves Liver Parameters in a Mouse Model of Nonalcoholic Fatty Liver Disease without Affecting Glucose or Body Weight"
}

\author{
The above article [Ookawara M, Matsuda K, Watanabe M, and Moritoh Y (2020) J Pharmacol \\ Exp Ther, 375: 21-27; DOI: https://doi.org/10.1124/jpet.120.000046] was originally incorrectly \\ published with an ASPET copyright line. The article should have been published under a CC \\ BY license. The HTML and PDF versions of the article have been corrected and the article is \\ freely accessible.
}

The compositor apologizes for any inconvenience caused by this error. 